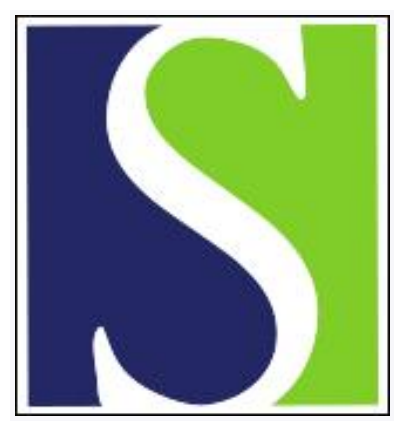

Scand J Work Environ Health 1990;16(3):169-174

https://doi.org/10.5271/sjweh.1797

Issue date: 01 Jun 1990

Risk of spontaneous abortion among Danish pharmacy assistants.

by Schaumburg I, Olsen J

Affiliation: Department of Social Medicine, University of Odense, Denmark.

This article in PubMed: www.ncbi.nlm.nih.gov/pubmed/2382119

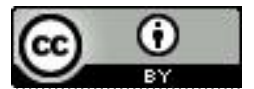




\title{
Risk of spontaneous abortion among Danish pharmacy assistants
}

\author{
by Inger Schaumburg, MD, ${ }^{1}$ Jørn Olsen, $\mathrm{MD}^{2}$
}

\begin{abstract}
SCHAUMBURG I, OLSEN J. Risk of spontaneous abortion among Danish pharmacy assistants. Scand $J$ Work Environ Health 1990;16:169-74. A national study of the risk of medically verified spontaneous abortion was conducted among all pharmacy assistants in Denmark. The cohort was defined as 4939 female members of the Association of Danish Pharmacy Technicians between 1979 and 1984, all under the age of 40 years. Data on spontaneous and induced abortions, and births as well, were obtained from the national registers from the same time period. Data on work history and exposure to pharmaceuticals and chemicals were collected from self-administered postal questionnaires in April 1985 with a response rate of $93 \%$. Studies of spontaneous abortion give rise to many methodological problems. In this study data were analyzed in a case-referent model using pharmacy assistants in administration and at the counter as the reference group. Generally, pharmacy assistants are at low risk with respect to spontaneous abortion. However, a few statistically significant results were found, but a decision on their importance must await further research.
\end{abstract}

Key terms: antibiotics, occupational exposure, pharmaceutical industry, pharmacy, reproductive outcome.

In recent years, several papers have addressed the issue of possible reproductive hazards of occupational and environmental exposures. (For a review, see references 1 and 2). In the present investigation, spontaneous abortions verified at hospitals were studied among all pharmacy assistants in Denmark.

Danish pharmacy assistants have been reported to have a higher risk of infertility due to hormonal disturbances (3) and a borderline prolonged time to pregnancy when exposed to antibiotics (4). Occupation in Swedish pharmaceutical laboratories appeared to be associated with a slightly increased risk of spontaneous abortion when compared with other occupations in the same industry (5). In a Finnish study of workers in the pharmaceutical industry a higher risk of spontaneous abortion was found among female workers exposed to methylene chloride (a solvent) and to estrogens (6). Finnish nurses exposed to cytostatics had an increased risk of spontaneous abortion (7) and of congenital malformation in their offspring (8). An increased risk of spontaneous abortion was found among women in the pharmaceutical industry in Finland, but the numbers were few (9), and in Italy no association was found (10).

\footnotetext{
1 Institute of Community Health, Department of Social Medicine, University of Odense, Denmark.

2 Institute of Social Medicine, University of Aarhus, Denmark.
}

Reprint requests to: Dr I Schaumburg, Institute of Community Health, Department of Social Medicine, University of Odense, JB Winsløws Vej 17, DK-5000 Odense C, Denmark.
Without any doubt pharmacy assistants work with chemical substances which may be harmful during pregnancy. The problem is more of whether existing safety regulations are sufficient to protect the workers. The objective of this study was to compare the risk of clinically recognized spontaneous abortions in different subgroups of pharmacy assistants according to type of work and chemical exposure. The present study is part of a larger investigation concerning several types of reproductive outcome among pharmacy assistants in Denmark.

A prerequisite for working as a pharmacy assistant in Denmark is a formal training of three years as an apprentice at a pharmacy and theoretical courses in pharmacology and human biology. Once licensed, all pharmacy assistants have to join the union (The Association of Danish Pharmacy Technicians) in order to be employed at a pharmacy. A small proportion of pharmacy assistants $(8 \%)$ work in the pharmaceutical industry, where they have the choice of being a member of this union (about $75 \%$ ) or another union. The work entails the following work tasks: production work, dispensary work, product control, packing, and counter work. In Denmark a large amount of ordinary drugs and mixtures was produced in factories but packed in glasses or bottled at the pharmacy during the study period. Besides, many extemporaneous preparations or chemical products used by dermatologists, veterinarians, or dentists are produced or prepared at the pharmacy.

Some types of work lead to exposure to pharmaceutical products, solvents, heavy metals, etc, whereas others lead to less or no exposure. Pharmacy assistants mainly occupied at the counter or in administration are considered less exposed, and this category has been used as a reference group in our study. 


\section{Subjects and methods}

A historical cohort with open entry was formed of all the women who had been a member of the national union of pharmacy assistants in Denmark at some time between 1 January 1979 and 31 December 1984 and who were under the age of 40 years on 31 December 1978. The study population was ascertained from the computerized membership file.

Data on exposure were collected by means of a postal questionnaire mailed to 4939 pharmacy assistants in April 1985 and followed by three reminders. A total of $4585(93 \%)$ returned the questionnaire. Questions were asked about work experience during pregnancy, type of pharmacy, type of work, and exposure to drugs and chemicals.

Data on births and induced and spontaneous abortions were obtained by linkage to the national registers on birth certificates and in-patients by means of the personal identification numbers of the subjects. All births and abortions recorded in 1979-1984 were included in the study. Women with a spontaneous abortion after the seventh to eighth week of gestation are almost all treated in hospitals in Denmark. Spontaneous abortions were not treated in outpatient clinics or in general practice during the study period. A few induced abortions were treated in outpatient clinics and not recorded in the register (estimated to be less than $5 \%$ ).

Data on spontaneous and induced abortions were obtained from the National In-patient Register, which includes the codes of the eighth revision of the International Classification of Diseases. In this study spontaneous abortions were defined according to diagnosis numbers 643 (abortus spontaneous) and 645 (abortus alius). In addition, three cases with diagnosis number 644 (unspecified abortion), nine cases of 634.61 (missed abortion), and four cases of 632.39 (abortus imminens) not followed by $a$ birth or an induced abortion were also included in the group of spontaneous abortions. In all these cases the women reported the abortion to be spontaneous. Induced abortions were defined as diagnosis numbers $640-642$, but none had a diagnosis number of 642 (illegal abortion). All births are registered in the Danish Medical Birth Register, which is considered to be complete (11).

The unit of analysis in the present context is a pregnancy, a link between a recording in the national registers and self-reported data on exposure. The number of pregnancies in the analyses was 2168 (1882 births, 177 spontaneous abortions, and 109 induced abortions), among 1651 women. Only women working during pregnancy for more than one week were included in the analyses.

Twenty-three of the spontaneous abortions found in the in-patient register were not reported in the questionnaires. Of these 10 occurred in 1979, the first year of the study period, and uncertainty about pregnancy time and start of the observation period could perhaps be an explanation. One hundred and forty-three registered induced abortions were not recorded in the questionnaires, and $25 \%$ of these occurred in 1979. Missing information on exposure during pregnancy for a large number of induced abortions led to the exclusion of this group.

The study was a historical cohort investigation using existing registers to identify pregnancies and pregnancy outcomes. In comparisons of spontaneous abortions with births, time-dependent exposure data would not necessarily be comparable, due to unequal follow-up periods in the groups to be compared, and it cannot be ruled out that specific data on exposure could be influenced by the length of observation time. For this reason, and due to the inability to define the study base directly, spontaneous abortions have also been compared with pregnancies during which the woman worked less than five months, with the use of a casereferent approach.

The data were analyzed with an unconditional logistic regression model. All the indicated confidence intervals are $95 \%$ confidence intervals.

\section{Results}

The frequency of spontaneous abortion is shown in table 1 according to type of pharmacy. Spontaneous abortion was more frequent (borderline significance)

Table 1. Spontaneous abortions according to type of pharmacy. (OR=odds ratio, $95 \% \mathrm{Cl}=95 \% \mathrm{Cl}$ confidence interval)

\begin{tabular}{|c|c|c|c|c|c|c|c|c|c|c|}
\hline \multirow{3}{*}{$\begin{array}{l}\text { Type of } \\
\text { workplace }\end{array}$} & \multicolumn{2}{|r|}{ Births } & \multicolumn{2}{|c|}{ Abortions } & \multicolumn{2}{|c|}{ Unadjusted OR } & \multicolumn{4}{|c|}{ Adjusted $O^{a}$} \\
\hline & \multirow[t]{2}{*}{ All } & \multirow{2}{*}{$\begin{array}{c}\text { Among women } \\
\text { with }<5 \text { months } \\
\text { of work during } \\
\text { pregnancy }\end{array}$} & \multirow[t]{2}{*}{ Induced } & \multirow{2}{*}{$\begin{array}{l}\text { Sponta- } \\
\text { neous }\end{array}$} & \multirow{2}{*}{$\begin{array}{c}\begin{array}{c}\text { All } \\
\text { births }\end{array} \\
\text { OR }\end{array}$} & \multirow{2}{*}{$\begin{array}{l}\text { Births among } \\
\text { women with } \\
<5 \text { months of } \\
\text { work during } \\
\text { pregnancy } \\
\text { OR }\end{array}$} & \multicolumn{2}{|c|}{ All births } & \multicolumn{2}{|c|}{$\begin{array}{l}\text { Births among women } \\
\text { with }<5 \text { months } \\
\text { work during pregnancy }\end{array}$} \\
\hline & & & & & & & OR & $95 \% \mathrm{Cl}$ & OR & $95 \% \mathrm{Cl}$ \\
\hline $\begin{array}{l}\text { Rural pharmacy } \\
\text { Urban pharmacy } \\
\text { Hospital pharmacy } \\
\text { Other (reference) }\end{array}$ & $\begin{array}{r}439 \\
1117 \\
75 \\
251\end{array}$ & $\begin{array}{l}25 \\
73 \\
10 \\
23\end{array}$ & $\begin{array}{l}19 \\
50 \\
13 \\
27\end{array}$ & $\begin{array}{r}31 \\
116 \\
6 \\
24\end{array}$ & $\begin{array}{l}0.7 \\
1.3 \\
0.8 \\
1.0\end{array}$ & $\begin{array}{l}0.9 \\
1.5 \\
0.4 \\
1.0\end{array}$ & $\begin{array}{l}0.5 \\
1.4 \\
1.0 \\
\cdots\end{array}$ & $\begin{array}{c}0.3-0.8 \\
1.0-2.1 \\
0.4-2.5 \\
\cdots\end{array}$ & $\begin{array}{l}0.7 \\
1.7 \\
0.4 \\
\cdots\end{array}$ & $\begin{array}{c}0.4-1.4 \\
1.0-2.8 \\
0.1-1.1 \\
\end{array}$ \\
\hline All & 1882 & 131 & 109 & 177 & $\cdots$ & $\cdots$ & .. & $\ldots$ & $\ldots$ & $\cdots$ \\
\hline
\end{tabular}

a Logistic regression model including age $(<25, \geq 25$ years), previous number of children $(0,1, \geq 2)$, smoking $(0,1-9,10-14, \geq 15$ cigarettes daily), drinking $(0, \geq 1$ drinks per week) during pregnancy. 
among pharmacy assistants working in towns when their number was compared to the total number of births or the number of births for which the woman worked less than five months. The analysis was adjusted for age, parity, smoking, and alcohol consumption.

The increased frequency of spontaneous abortion in urban pharmacies was not necessarily due to occupational exposure but could reflect additional differences in life-style and environmental factors associated with urban life. The women's responses to bleeding in pregnancy and the rate of hospitalization could also have differed among the women living in towns and those living in the country. For these reasons type of pharmacy was included in the statistical model in table 2 in addition to the potential confounders mentioned in table 1. An increased odds ratio $(1.5,95 \%$ confidence interval $1.0-2.3$ ) bordering on statistical significance

Table 2. Spontaneous abortions according to main type of work during pregnancy. $(\mathrm{OR}=$ odds ratio, $95 \% \mathrm{Cl}=95 \%$ confidence interval)

\begin{tabular}{|c|c|c|c|c|c|c|c|c|}
\hline \multirow{2}{*}{$\begin{array}{l}\text { Type of } \\
\text { work }\end{array}$} & \multicolumn{2}{|r|}{ Births } & \multicolumn{2}{|c|}{ Abortions } & \multicolumn{2}{|c|}{ All births } & \multicolumn{2}{|c|}{$\begin{array}{l}\text { Births among women } \\
\text { with }<5 \text { months of } \\
\text { work during pregnancy }\end{array}$} \\
\hline & All & $\begin{array}{l}\text { with }<5 \\
\text { months of } \\
\text { work during } \\
\text { pregnancy }\end{array}$ & Induced & $\begin{array}{l}\text { Sponta- } \\
\text { neous }\end{array}$ & $\mathrm{OR}^{\mathrm{a}}$ & $95 \% \mathrm{Cl}$ & $\mathrm{OR}^{\mathrm{a}}$ & $95 \% \mathrm{Cl}$ \\
\hline Reference work & 581 & 38 & 33 & 60 & 1.0 & $\cdots$ & 1.0 & $\cdots$ \\
\hline Production & 385 & 29 & 19 & 43 & $1.5^{\mathrm{b}}$ & $1.0-2.3$ & 1.1 & $0.6-2.0$ \\
\hline Dispensary & 536 & 36 & 23 & 41 & $0.9^{b}$ & $0.6-1.3$ & 0.7 & $0.4-1.3$ \\
\hline Identification & 79 & 6 & 6 & 3 & $0.8^{\mathrm{b}}$ & $0.3-1.9$ & 0.5 & $0.1-2.7$ \\
\hline $\begin{array}{l}\text { Bottling of } \\
\text { pharmaceuticals }\end{array}$ & 40 & 2 & 3 & 1 & $0.5^{b}$ & $0.1-2.3$ & 0.2 & $0.0-2.6$ \\
\hline $\begin{array}{l}\text { Packing of } \\
\text { pharmaceuticals }\end{array}$ & 111 & 6 & 1 & 9 & 0.8 & $0.4-1.7$ & 1.4 & $0.4-4.6$ \\
\hline Other & 150 & 14 & 24 & 20 & $2.2^{\mathrm{b}}$ & $1.2-4.0$ & 1.4 & $0.6-3.4$ \\
\hline All & 1882 & 131 & 109 & 177 & $\cdots$ & $\cdots$ & $\cdots$ & $\cdots$ \\
\hline
\end{tabular}

a Logistic regression analysis adjusted for parity $(0,1, \geq 2)$ and location of pharmacy (city, other)

b Additionally adjusted for mother's age $(<25, \geq 25$ years $)$, smoking $(0,1-9,10-14, \geq 15$ cigarettes daily), drinking $\langle 0$, $\geq 1$ drinks per week) during pregnancy.

Table 3. Spontaneous abortions according to daily or weekly exposure to unsealed drugs or chemicals during pregnancy. (OR $=$ odds ratio, $95 \% \mathrm{Cl}=95 \%$ confidence interval)

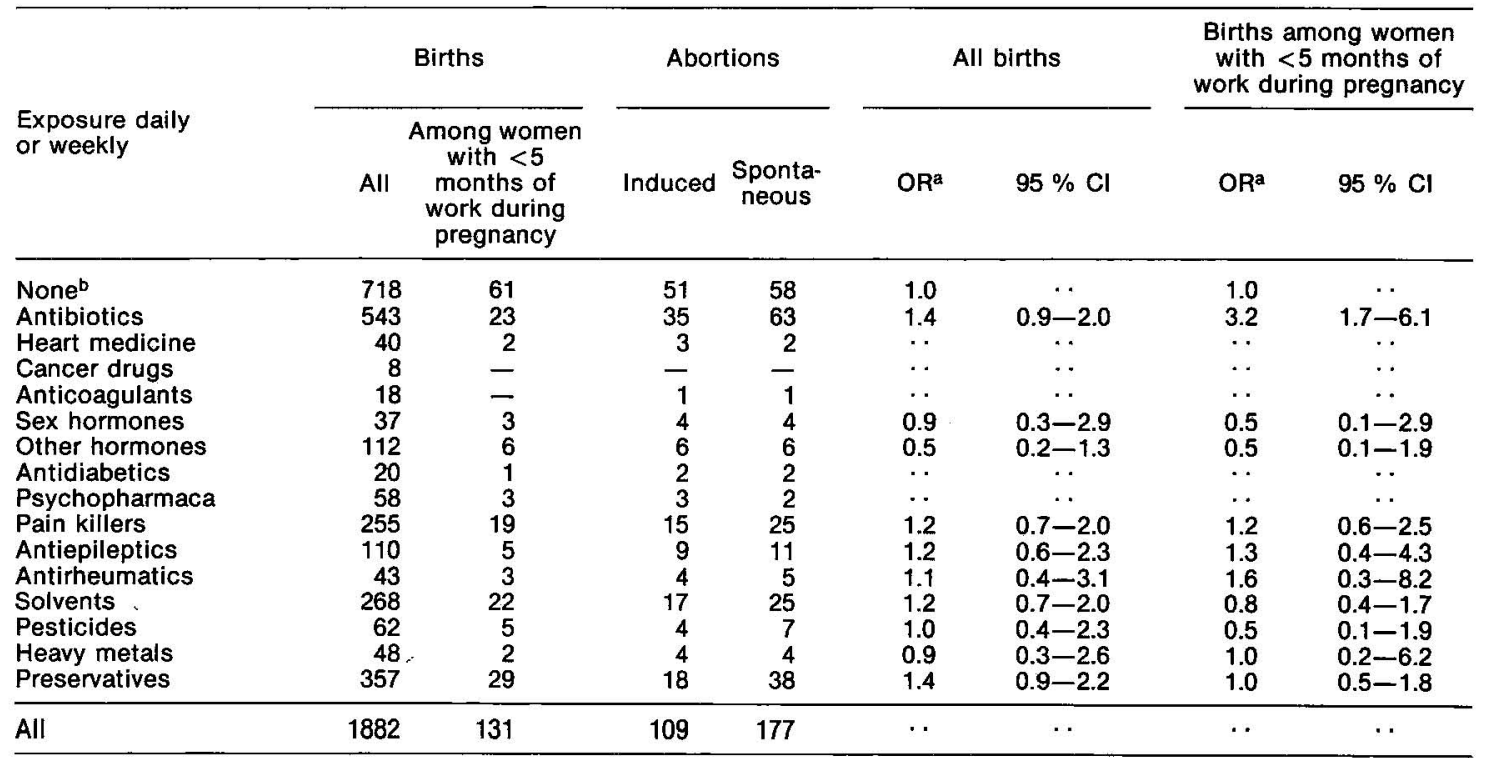

a Logistic regression, adjusted for parity $(0,1, \geq 2)$ and location of pharmacy (city, other); average exposure during pregnancy; each pregnancy may be recorded more than once.

b Women who did not report daily or weekly exposure to named pharmaceuticals or chemicals. The group was not completely unexposed. 
was found for spontaneous abortions among the women working in production when all births were used as the reference. In addition, a not significantly elevated odds ratio was seen when the number of spontaneous abortions was compared with the number of births among the women who worked less than five months during pregnancy.

"Other types of work" was associated with an odds ratio that was not significantly increased for spontaneous abortions in a comparison with births among the women who worked less than five months during pregnancy. However, when the comparison involved all births, the increase was statistically significant.

The frequencies of spontaneous abortion according to daily or weekly exposure in pregnancy to unsealed pharmaceutical products or chemicals in open boxes are listed in table 3. Exposure to antibiotics was related to a significantly increased frequency of spontaneous abortion when compared with births among the women who worked less than five months during pregnancy (odds ratio 3.2). A nonsignificantly elevated odds ratio was found when the comparison involved all births.

\section{Discussion}

This study concerned mainly spontaneous abortions after seven to eight weeks of gestation since very early abortions usually remain undetected by the woman or the health care system. A recent prospective study of 221 women intending to conceive showed that $31 \%$ of all pregnancies verified by the urinary concentration of human chorionic gonadotrophin were lost (12). Two-thirds of these pregnancies were lost even before the woman realized that she was pregnant. Thus exposures that would delay an early spontaneous abortion would appear as a "risk factor" in these analyses, and causes of very early spontaneous abortions only are not detectable in a study of this type. Since the recognition and registration of spontaneous abortion are vulnerable to differences in how women respond to bleeding in pregnancy, only women with a similar educational background have been compared.

This study includes hospital-diagnosed spontaneous abortions only, mainly to assure that any misclassification will be of the random type. The use of selfreported outcome data could be sensitive to recall bias (13). In our study 23 spontaneous abortions were not reported in the questionnaires. This number is rather small, but still the potential for selection bias due to nonresponse appears, as shown by Axelsson \& Rylander (14). If the women in production or the women exposed to antibiotics had had a higher response rate for spontaneous abortion, only then could bias have been introduced. The main type of work in the year of the abortion was available for all the women, and, with this information used as a proxy measure for exposure during pregnancy, a reanalysis did indicate a possibility of this type of bias, ie, an approximately $10 \%$ overestimation for the odds ratio. Only two of the unreported spontaneous abortions occurred in the "production" category. By reanalyzing the data in table 2, after inclusion of the nonresponders, we found no significant differences for type of work. An analysis of this type could not be performed for exposure during pregnancy.

Self-reported data on exposure may be sensitive to recall bias, and for this reason very detailed exposure data were not collected. However, in a recent study of recall bias among pregnant women (15), no evidence of any overreporting of exposure after delivery was found in a comparison with information given early in pregnancy.

The analyses in this study were performed as in casereferent studies, two different reference groups being used - pregnancies terminating as a single birth and pregnancies in which the woman worked less than five months during the pregnancy in question. The reference groups were used for the estimation of the distribution of exposure in the study base. Unfortunately, neither of these two groups were ideal in the sense that they would give an unbiased estimate of the proportion of exposed persons among the base group of women having an abortion. Comparing spontaneous abortions with all births meant that the observation times were different in the groups compared, and pregnant women with less than five months of work during pregnancy may have been on sick leave due to a disease related to exposure. We intended to use pregnancies ending as an induced abortion as a third reference group in order to minimize the problem of different lengths of observation during pregnancy. However, as about $50 \%$ of all induced abortions were not reported, the estimates would have been dubious. In addition, the result of such a comparison would be biased if the legal termination of pregnancy were related to the work situation under study (16).

Pharmacy assistants are generally a normal or lowrisk group with respect to spontaneous abortion, as only $9 \%$ of all registered conceptions in the study period (including pregnancies among nonresponding pharmacy assistants) terminated as a spontaneous abortion, whereas the value was $10 \%$ for all pregnant women in Denmark in 1980 to 1981 . The corresponding figures for induced abortions were even more divergent, with $12 \%$ induced abortions among pharmacy assistants and $27 \%$ among all Danish women $(17,18)$. Thus a comparison of pharmacy assistants with external reference groups could be invalid for several reasons. However, internal comparison among subgroups of pharmacy assistants according to job and occupational exposure did reveal a few differences in the risk of spontaneous abortion.

An increased frequency of spontaneous abortion in relation to work in urban pharmacies was found that bordered on statistical significance. This result may have been due to uncontrolled differences in life-style variables associated with urban life. On the other hand it could have been due to harmful occupational ex- 
posure, since urban pharmacies more often produce drugs.

Work in production was associated with a rise in the odds ratio for spontaneous abortion which bordered on statistical significance. Hemminki et al (9) found an increased risk of spontaneous abortion among chemical workers in the pharmaceutical industry in 1980 when the group was compared with all Finnish women, but the number of cases was few. Taskinen et al (6) found a decrease in the rate of spontaneous abortion that coincided with technical improvements decreasing dust and vapor exposure, but there was no increase in the frequency of spontaneous abortion among the female workers who were employed during the first trimester of pregnancy in comparison with the women not employed in the pharmaceutical industry.

When spontaneous abortions were analyzed according to daily or weekly exposure to pharmaceutical products or chemicals, no association or only weak associations were found. However, an increased frequency of spontaneous abortion was found among the women exposed to antibiotics (odds ratio 3.2) when this group was compared with women working less than five months during pregnancy. This result was unexpected and may be spurious. Nevertheless, Taskinen et al (6) found an increased odds ratio for spontaneous abortion (not significant) among women exposed to antibiotics, and also a borderline prolonged time to pregnancy $(P=0.05)$ has been reported for pharmacy assistants exposed to antibiotics (4). However, women exposed to antibiotics may also have been exposed to other pharmaceuticals, and the observed effect could be the result of a combined exposure.

Exposure to solvents was not associated with an increased risk of spontaneous abortion in this study, in contrast to several studies that have shown a relation between spontaneous abortion and laboratory work or exposure to solvents $(5,6,19)$. However, other researchers found results corresponding to ours (20, 21 ), and the differences in exposure could easily explain the different outcomes of the studies.

Monthly exposure to cytostatics was associated with an increased risk of spontaneous abortion (odds ratio 1.6), but the result was not statistically significant and rather uninformative due to the small numbers. Exposure to cytostatics has earlier been associated with an increased risk of spontaneous abortion among nurses (7).

Comparing spontaneous abortions among a group of pharmacy assistants according to type of pharmacy, work tasks, and exposure may have eliminated bias introduced by social or economic factors, as we have no reason to believe that there was any healthy worker, or sick worker, selection to the different types of work, but probably to work as such. However, the price paid was that the work conditions of the studied groups were similar, and thus the exposure contrasts were less than satisfactory. Furthermore, the exposure data were rather crude and could have biased the results towards unity since no completely unexposed group was available in this study.

In the statistical analyses pregnancy outcomes were treated as independent events, and repeated pregnancies among the participating women were not taken into consideration. However, as each woman in this study contributed only a few pregnancies, ie, 1.3, the impact on the magnitude of the estimates was considered to be minor (22).

Controlling for confounding was only possible to some extent. However, none of the variables age, parity, smoking, or drinking habits proved to have strong confounding properties.

\section{Acknowledgments}

This paper was made possible by the efficient cooperation of the Association of Danish Pharmacy Technicians. The thorough and constructive criticism of Professor K Kristoffersen and Dr S Lings is gratefully acknowledged.

This work was supported by a grant from the Danish Work Environment Fund (1984/14) and The Danish Medical Research Council (12-5075).

\section{References}

1. McDonald AD. Work and pregnancy. Br J Ind Med 1988;45:577-80.

2. Rosenberg MJ, Feldblum PJ, Marshall EG. Occupational influences on reproduction: a review of recent literature. J Occup Med 1987;29:584-91.

3. Rachootin P, Olsen J. The risk of infertility and delayed conception associated with exposures in the Danish workplace. J Occup Med 1983;25:394-402.

4. Schaumburg I, Olsen J. Time to pregnancy among Danish pharmacy assistants. Scand J Work Environ Health 1989;15:222-6.

5. Hansson E, Jansa S, Wande H, Källén B, Östlund E. Pregnancy outcome for women working in laboratories in some of the pharmaceutical industries in Sweden. Scand J Work Environ Health 1980;6:131-4.

6. Taskinen $\mathrm{H}$, Lindbohm ML, Hemminki K. Spontaneous abortions among women working in the pharmaceutical industry. Br J Ind Med 1986;43:199-205.

7. Selevan SG, Lindbohm ML, Hornung RW, Hemminki K. A study of occupational exposure to antineoplastic drugs and fetal loss in nurses. N Engl J Med 1985;313: $1173-8$.

8. Hemminki K, Kyyrönen P, Lindbohm ML. Spontaneous abortions and malformations in the of fspring of nurses exposed to anaesthetic gases, cytostatic drugs, and other potential hazards in hospitals, based on registered information of outcome. J Epidemiol Community Health 1985;39:141-7.

9. Hemminki K, Franssila E, Vainio H. Spontaneous abortions among female chemical workers in Finland. Int Arch Occup Environ Health 1980;45:123-6.

10. Figá-Talamanca I. Spontaneous abortions among female industrial workers. Int Arch Occup Environ Health 1984;54:163-71.

11. Knudsen LB, Kristensen FB. Monitoring perinatal mortality and perinatal care with a national register: content and usage of the.Danish medical birth register. Com- 
munity Med 1986;8:29-36.

12. Wilcox AJ, Weinberg CR, O'Connor JK, et al. Incidence of early loss of pregnancy. N Engl J Med 1988;319: 189-94.

13. Axelsson G, Rylander R. Validation of questionnaire reported miscarriage, malformation and birth weight. Int J Epidemiol 1984;13:94-8.

14. Axelsson G, Rylander R. Exposure to anaesthetic gases and spontaneous abortions: response bias in a postal questionnaire study. Int J Epidemiol 1982;11:250-6.

15. Mackenzie SG, Lippman A. An investigation of report bias in a case-control study of pregnancy outcome. Am J Epidemiol 1989;129:65-75.

16. Olsen J. Calculating risk ratios for spontaneous abortions: the problem of induced abortions. Int J Epidemiol 1984;13:347-9.

17. Sundhedsstyrelsen. Medicinsk fødselsstatistik 1981: vital statistik I:13:1985 [Medical birth statistics 1981: vital statistics I:13:1985]. Copenhagen: Sundhedsstyrelsen, 1985.
18. Andreasen EE. Fødsler, aborter og ekstrauterine graviditeter i Fyns Amt i perioden 1974-1986 [Births and abortions in the county of Funen during the period 1974-1986]. Ugeskr Læger 1989;151:384-7.

19. Strandberg M, Sandbäck K, Axelson $O$, Sundell L. Spontaneous abortions among women in a hospital laboratory. Lancet 1978;2:384-5.

20. Axelsson G, Lütz C, Rylander R. Exposure to solvents and outcome of pregnancy in university laboratory employees. Br J Ind Med 1984;41:305-12.

21. Heidam LZ. Spontaneous abortions among laboratory workers: a follow up study. J Epidemiol Community Health 1984;38:36-41.

22. Butler WJ, Kalasinski LA. Statistical analysis of epidemiologic data of pregnancy outcomes. Environ Health Perspect 1989;79:223-7.

Received for publication: 17 July 1989 